\title{
Testigos modestos y poblaciones invisibles en la cobertura de la genética humana en los medios de comunicación colombianos*
}

\author{
Adriana Díaz del Castillo ${ }^{1 * *}$ \\ María Fernanda Olarte Sierra ${ }^{2}$ \\ Tania Pérez-Bustos ${ }^{3}$
}

DÍAZ DEL CASTILLO, A.; OLARTE SIERRA, M.F.; PÉREZ-BUSTOS, T. Modest witnesses and invisible populations in media coverage of human genetics in Colombia. Interface - Comunic., Saude, Educ., v.16, n.41, p.451-67, abr./jun. 2012.

In this paper we explore the ways in which mass media present -and coproduce- human genetic research in Colombia, reproducing certain standardized discourses about science which are cross-cut by gender and race. For this, we conducted an ethnographic analysis of media coverage of human genetics (both population and forensic) in two of the major media in Colombia between 1992-2006 (newspaper) and 2009-2010 (TV news). Our argument is two-fold. First we show that media present genetic science as unique/ uniform/objective/neutral/heroic. Second, media present subjects as simultaneously marked and unmarked in terms of race, gender, class, and geography. We conclude by arguing that this mechanism reproduces and mobilizes the ideal of mestizaje as a nation-building ideology in Colombia.

Keywords: Modestwitness. Humangenetics. Media. Mestizo. Cultural anthropology.
En este artículo exploramos cómo los medios de comunicación colombianos configuran la práctica de la genética humana, reproduciendo ciertos discursos estandarizados sobre ciencia que se encuentran atravesados por el género y la raza. Para este fin llevamos a cabo un análisis etnográfico de la cobertura de la genética humana (poblacional y forense) en dos de los medios de mayor penetración en el país en los periodos de 1992-2006 (periódico) y 2009-2010 (periódico y noticiero). Nuestro argumento es que por una parte, los medios de comunicación presentan a la ciencia genética como única/uniforme/ objetiva/neutra/heroica. Por otro lado, presenta sujetos que son simultáneamente marcados y desmarcados en términos de raza, género, clase y geografía. Concluimos que este último mecanismo reproduce y moviliza la idea del mestizaje como una ideología de construcción de nación.

Palabras clave: Testigo modesto. Genética humana. Medios. Mestizo. Antropología Cultural.
"Artículo en el marco de dos proyectos de investigación. El proyecto "Ciencia y medios: un estudio comparativo de la cobertura de la ciencia en los noticieros de televisión de Brasil y Colombia", financiado por la Pontificia Universidad Javeriana y el programa CYTED y la investigación

"Raza, genómica y mestizaje en Latinoamérica: una perspectiva comparativa", financiado por el Consejo de Investigación Económica y Social (ESRC) y la Universidad de Manchester. El primer proyecto analiza críticamente la cobertura en medios de temáticas relacionadas con ciencia y tecnología. El segundo proyecto estudia cómo ideas de raza y nación permean la práctica genética y cómo esas ideas se presentan en la esfera

pública. Para Colombia este escenario se definió desde los medios de comunicación.

"El orden de las autoras corresponde al orden alfabético y no hace referencia a jerarquías o diferencias en contribución.

1,2 Universidad de los Andes. Av. Cll 39, no 8-65, apto. 1001, Edificio Tequenusa 1. Bogotá, Colombia. adiazdelc@gmail.com ${ }^{3}$ Departamento de Antropología, Pontificia Universidad Javeriana 
El objetivo principal de este artículo es ahondar en la comprensión sobre cómo la práctica de la genética es configurada por los medios de comunicación, reproduciendo ciertos discursos estandarizados sobre ciencia que se encuentran atravesados por el género y la raza. Este acercamiento a los medios implica concebirlos como dispositivos pedagógicos que tienen el poder de vehiculizar (y estandarizar) discursos hegemónicos sobre la subjetividad (Bueno Fischer, 2002). Como argumentaremos, entendemos que estos escenarios son atravesados por discursos en torno a la raza y el género. Esto ocurre de modos particulares en lo que respecta a la comunicación sobre la genética humana en un país como Colombia, en donde el conflicto armado y la inequidad social configuran los modos como se presentan públicamente la genética forense y poblacional.

Investigaciones recientes que, con algunas excepciones (Massarani, Moreira, Magalhães, 2003), han estado principalmente localizadas en países considerados hegemónicos en la producción de conocimiento científico, dan cuenta del lugar que la genética humana ocupa actualmente en los medios masivos de comunicación (Pin, Gutteling, 2009). En su mayoría, estos trabajos dan cuenta de las representaciones de la genética humana con aplicaciones médicas en la prensa escrita o en los noticieros televisivos (Hivon et al., 2005; Eyck, 2005; Bubela, Caulfield, 2004; Mountcastle-Shah et al., 2003; Petersen, 2001; Henderson, Kitzinger, 1999). En menor frecuencia, también se encuentran estudios sobre la cobertura mediática de la genética poblacional. En esta dirección están los trabajos sobre el cubrimiento noticioso de proyectos sobre bancos de genes principalmente en Europa (Tammpuu, 2004; Costa, 2003), las reflexiones sobre la relación entre genética humana y el discurso de lo natural en los medios (Hansen, 2006) y las reflexiones en torno a la genética poblacional, su cobertura mediática y las implicaciones de esta intersección en la construcción de identidades nacionales (Parfitt, Egorova, 2006) y sexuales (Kitzinger, 2005).

Son varios los vacíos que deja ver este breve panorama. Primero, vale señalar la ausencia de reflexiones sobre la genética en los medios en contextos de producción de conocimiento considerados no hegemónicos, en donde ubicaríamos a Colombia. Por otro lado, a pesar de la creciente investigación antropológica sobre la interacción entre genética y raza (Koening, Lee, Richardson, 2008; Wade, 2007; Pena, 2005; Santos, Maio, 2005), es interesante que la mayoría de estas reflexiones no hayan generado preguntas sobre cómo esto se encuentra presente en la esfera pública de los medios, entendiendo éstos como espacios en los que se ponen en escena dinámicas culturales particulares y que por tanto ameritan una aproximación etnográfica.

\section{Anotaciones metodológicas}

Como señalamos, este estudio analiza etnográficamente los medios masivos de comunicación de mayor penetración en Colombia, con énfasis en la información noticiosa de prensa y televisión. El propósito era identificar cómo estos escenarios presentan, y por tanto construyen, la genética forense y poblacional. En este sentido, asumimos que esta presentación de la genética es un proceso de comprensión pública del conocimiento científico que está atravesado por dinámicas culturales. Al entender estos medios de comunicación como escenarios que hacen parte de la periferia de la producción de conocimiento, en la periferia, asumimos que ellos contribuyen a reproducir ciertas nociones de ciencia hegemónicas, poniéndolas a circular localmente, ratificándolas. Pero ello también quiere decir que éstos son escenarios en los que culturalmente se producen formas particulares de hacer ciencia local (Haraway, 1995).

Iniciamos nuestra etnografía de la información noticiosa, a través de una exploración del noticiero de mayor raiting en Colombia, Noticas Caracol 7 pm, rastreando entre abril, 2009 y abril, 2010 aquellas noticias que referían a la genética poblacional y forense ${ }^{4}$. Esto fue complementado con una exploración del periódico El Tiempo versión digital durante el mismo período. En televisión se identificaron 3 noticias y en el periódico $36^{5}$. En este proceso evidenciamos que la mayor información que circula (en noticieros y diarios) refiere a genética forense asociada o bien al proceso de la ley de Justicia y $\mathrm{Paz}^{6}, \mathrm{o}$ bien a crímenes comunes. Considerando que en el primer período analizado no se encontraron referencias a genética poblacional, hicimos un rastreo de este tema en El Tiempo.com e identificamos 
${ }^{4}$ Las noticias seleccionadas se identificaron usando la metodología de "semana construida" (Krippendorff, 1990; Stempel, Westley, 1989). Considerando una semana construida por mes. La muestra equivale a 12 semanas construidas en el año y 84 programas en donde se identificaron

las noticias relacionadas

con genética poblacional $y$ forense.

${ }^{5}$ Para noticias caracol, las noticias identificadas fueron del: 12 y 16 de febrero y 31 de marzo del 2010. Para El Tiempo las noticias fueron: para el 2009,18 y 29 de abril,

$13,21,26$ y 29 de mayo, 16 de julio, 3 y 8 de agosto, 4, 7 y 18 de septiembre - con dos noticias el $4-, 6,3,4$ y 15 de octubre - con 4 noticias el $15-, 6,16$ y

27 de noviembre y 11 y

28 de diciembre. Para el

2010, 14 de enero, 3 ,

10,19 y 25 de febrero con 2 noticias el 3 - y 3 , 5 y 10 de marzo y 10 de abril.

${ }^{6}$ La ley de Justicia, Paz y Reparación se creó en el marco de la política

Seguridad Democrática en la administración 20062010 en Colombia. Su objetivo era "facilitar los procesos de paz y la reincorporación individual o colectiva a la vida civil de miembros de grupos armados al margen de la ley, garantizando los derechos de las víctimas a la verdad, la justicia y la reparación". Dentro de los actos de "reparación", se incluye "la búsqueda de los desaparecidos y de los restos de personas muertas, y la ayuda para identificarlos y volverlos a inhumar según las

tradiciones familiares y comunitarias" (Colombia, 2005).

${ }^{7}$ Los diarios El Tiempo de 31 de agosto y 4 de octubre de 1992, febrero 1 de 1993, 30 de julio y 27 de agosto de 2000, 11 de octubre de 2002, 20 y 21 de enero, octubre 12, 13 y 30 - con dos noticias el 13, y noviembre 3 y 12 de 2006. un total de 15 noticias entre 1992 y 20067. Para este caso fue notorio la relación de estas noticias con el boom del proyecto llamado Expedición Humana ${ }^{8}$ y con la publicación de artículos que refieren a otros proyectos específicos de genética poblacional realizados por genetistas colombianos.

\section{Derroteros teóricos y pistas de lectura}

Al analizar etnográficamente la información sobre genética humana identificada en los medios, encontramos que éstos ayudan a movilizar un ideal particular de conocimiento científico de carácter hegemónico. Si bien estas representaciones han sido ampliamente criticadas por los Estudios Sociales de la Ciencia y la Tecnología (ESCT) de perspectiva constructivista (Irwin, Wynne, 1996; Law, 1991; Bijker, Hughes, Pinch, 1999; Latour, 1987), ellas se encuentran particularmente arraigadas en las representaciones sociales y en los imaginarios públicos sobre este conocimiento (Pérez-Bustos, 2010; Henwood, Parkihill, Pidgeon, 2008; Gallego, 2007; Fernández et al., 2002). Desde las preguntas que orientan esta investigación, vemos esta representación de la genética como atravesada por un discurso particular de raza y de género.

Retomando a Haraway (2004) encontramos que la genética presentada en las noticias identificadas, se encuentra en estrecho diálogo con lo que Haraway identifica como la ciencia hegemónica del siglo XVII y XVIII en Europa. En este sentido, comprendemos a los medios como dispositivos con el poder de estandarizar y globalizar un ideal de conocimiento científico producido desde un lugar invisible y por sujetos invisibles; sujetos neutrales desmarcados de raza y género, cuya palabra siempre es veraz y definitoria con el poder heroico de resolver problemas de manera aséptica y estandarizada, sin involucrarse con el contexto social (Kruse, 2010).

Esta representación "limpia" de ciencia reproduce (localmente) los atributos de un "testigo modesto" (Haraway, 2004), un caballero distante que a través de experimentos estandarizados explica fenómenos físicos que se constituyen en espejos de la realidad. Este testigo modesto es representante de una ciencia moderna/occidental/blanca/masculina cuyo poder está amparado en una serie de trucos de auto-invisibilización. Es decir, que puede explicar la realidad, en parte porque él mismo, su lugar de enunciación blanco/occidental/masculino, es invisible; pero también porque al explicarla invisibiliza a otros, les quita estatuto epistemológico. Esto ocurre en parte por considerarlos adversos a la norma que el testigo modesto define desde sí.

Sostenemos que estos trucos de auto-invisibilización se caracterizan en los medios a través de una representación pendular de la genética poblacional y forense. Por un lado, encontramos que este conocimiento experto aparece como un espejo de esa ciencia blanca/occidental/europea/moderna/masculina, marcaciones que sin embargo son invisibles - tanto para la ciencia hegemónica, así como para su representación mediática. Llamamos a este proceso discursivo una "marcación/desmarcada", que dialoga con el estatuto de invisibilidad de los científicos europeos, los testigos modestos de los que nos habla Haraway (2004), y que para nuestro caso, estaría representado en científicos locales, como sujetos "blanqueados", que, al igual que aquellos, asumen un lugar de enunciación neutral, desde donde comprenden asépticamente el mundo que interpretan. Y que al hacerlo utilizan, sin involucrarse, dispositivos culturales de "marcación/ desmarcación" para analizar e identificar al otro que estudian. Como veremos en el análisis de las noticias, esta tensión entre sujetos "blanqueados" invisibles que 
marcan a otros y que lo hacen de modo aséptico (desmarcando), para no comprometerse manteniéndose neutrales, dialoga con el estatuto del mestizo en Colombia, como una ideología que ha pretendido unificar, homogeneizar y borrar diferencias raciales (aunque al mismo tiempo enfatiza estas diferencias y genera exclusión) (Múnera apud Arocha, Moreno, 2007; Serrano, Viveros, 2006; Wade, 2005; Mallon, 1996).

\section{Coordenadas analíticas}

Antes de desarrollar estos argumentos, profundizaremos en las categorías analíticas que utilizamos para abordar las noticias: el estatuto de modestia y el movimiento pendular desmarcación/marcación/desmarcación. Vemos estas categorías como mecanismos que ayudan a movilizar el ideal de genética ya presentado.

Una primera categoría refiere al estatuto de modestia, el cual comprendemos desde la noción de brevedad, en estrecho diálogo con el carácter heroico de la ciencia. Como veremos en los apartados que siguen, las referencias encontradas sobre la genética en las noticias son puntuales, apareciendo mencionada una sola vez. Esta pequeña referencia suele estar inmersa en noticias que tratan sobre otros asuntos y no sobre la genética en sí, su quehacer o su proceso. En el caso forense, por ejemplo, la brevedad aparece en la corta alusión a las pruebas de ADN que corroboran la identidad de un cuerpo. Esta referencia se pierde luego en detalles sobre la desaparición de la persona, la guerra y los eventos que llevaron a la recuperación del cuerpo, como veremos en detalle más adelante. Sin embargo, si bien esta referencia a la genética (a las pruebas de ADN) es breve, en la narrativa de la noticia siempre tiene la misma funcionalidad: resolver un drama personal y nacional. En este sentido, la referencia es breve pero es definitoria y poderosa. Puesto de otra manera, es justamente esa brevedad la que le confiere poder. En este contexto, asociamos este concepto con la idea de Latour (1990), sobre la manera como la ciencia moderna occidental opera desde una serie de ideas y representaciones del mundo que se estandarizan y se vuelven inmutables, las cuales luego adquieren poder a través de una puesta en circulación que ocurre a través de unos dispositivos móviles frágiles. Sobre el poder de las movilizaciones de inmutables realizadas a través de la prensa, Latour (1990) resalta que ésta permite movilizar e inmutabilizar elementos, procedimientos, argumentos, cifras, mapas, genes y, en nuestro caso, las pruebas de ADN para identificar un cuerpo. Encontramos interesante como, por medio de la movilización en prensa y de la brevedad de la referencia, la genética forense - en este caso las pruebas de ADN adquiere un poder de carácter absoluto. Esta categoría - brevedad y modestia - la ilustraremos en la segunda parte de este artículo.

La segunda categoría refiere al movimiento pendular desmarcación/marcación/ desmarcación, que se encuentra asociado al atributo modesto de la genética ya explicado. Como veremos en el análisis, en la narrativa de las noticias la ciencia se presenta como un ejercicio de descubrimiento más no de construcción o de coproducción; ni con el entorno, ni con los científicos que realizan el trabajo de análisis de datos e interpretación de resultados. No hay explicación de ningún tipo sobre los procesos de esta ciencia y esa falta de aclaraciones, ese asumir que la práctica genética es una, reproduce la ilusión de la singularidad y objetividad de la ciencia en general y reproduce a los científicos como seres al margen de la acción, como simples testigos y traductores de la revelación de la naturaleza. Desde esa narrativa, la ciencia genética tiene la tendencia a aparecer como una ciencia que
${ }^{8}$ La Expedición Humana refiere a un proyecto abanderado por el Instituto de Genética de la Universidad Javeriana, que inició en 1982 y cuyo objetivo fue encontrar variantes genéticas de los colombianos, con miras a desarrollar aplicaciones médicas que pudieran dar solución a enfermedades endémicas de las regiones visitadas. Las principales poblaciones mapeadas por este proyecto fueron grupos indígenas $y$ negros. Ver: <http:// www.javeriana.edu.co/ Humana/humana.html> 
en su ejercicio de identificar a los otros, lo hace sin comprometerse ni ponerse en evidencia. Se mantiene neutral e invisible - desmarcada. Como hemos señalado, este lugar de enunciación es homólogo con el estatuto hegemónico del mestizo, en tanto que ideología que unifica y borra diferencias, estableciendo un "nosotros" y un "ellos". Siendo el "nosotros" aquellos sujetos desmarcados que identifican - los científicos - y el "ellos", los sujetos que es necesario identificar, marcar - las víctimas, las poblaciones que son "otras". Es preciso, sin embargo, considerar que este ejercicio de marcación de "otros", no se despoja de su estatuto de modestia; del artilugio de volver tal marcación invisible, de auto-desmarcarla. Allí el movimiento pendular al que nos referiremos con ejemplos en la tercera parte de este artículo.

\section{La genética invisible}

A continuación presentamos un ejemplo de cómo aparecen en los medios estos dos elementos: el de la brevedad y el del carácter heroico de la ciencia y la naturaleza modesta de los científicos.

Presentamos una noticia como ejemplo, aunque tanto en las tres noticias televisadas como en las 35 de prensa, es similar la presentación de la genética y de los científicos. La siguiente noticia refiere a la identificación y posterior devolución del cuerpo del Mayor Guevara. La noticia fue televisada en marzo 31 de 2010 y posteriormente publicada por El Tiempo.com el 1 de abril. Por motivos de claridad y para presentar una sola versión de la noticia, usaremos la versión en prensa.

\section{Hoy la misión es traer los restos de Guevara}

A las 6 de la tarde de ayer comenzó la cuenta regresiva para el operativo que debe cerrar una de las más dolorosas historias del secuestro en Colombia: el del mayor Julián Ernesto Guevara, muerto en cautiverio hace cuatro años y cuyos restos aún no han sido devueltos por las Farc.

A esa misma hora, doña Emperatriz, la madre del oficial, abordaba en Bogotá un avión de la Policía con rumbo a Villavicencio. Allí está programada la salida de la misión humanitaria y, luego, la entrega de los restos...

... Aún no está definido si la familia tendrá un tiempo para tenerlos o si se hará una ceremonia de entrega simbólica para luego dejarlos al CTI de la Fiscalía y el Instituto Nacional de Medicina Legal.

El hecho es que un laboratorio forense determinará antes de una semana, por pruebas de ADN, si se trata realmente del mayor Julián Ernesto Guevara Castro. Hace dos meses Medicina Legal le tomó a doña Emperatriz una prueba de sangre que será cotejada con el ADN de los despojos. Ella le dijo ayer a EL TIEMPO que confía en que por fin, después de dos anuncios fallidos y uno que aún no se concreta, podrá enterrar a su hijo y cerrar el doloroso capítulo del secuestro y la muerte de su hijo...

...Un equipo integrado por la Fiscalía y Medicina Legal tendrá a su cargo la tarea de establecer, en los próximos días, si los restos que se recogerán en las coordenadas que entregaron las Farc corresponden a Julián E. Guevara. En el grupo hay profesionales en genética, patología, antropología y odontología, entre otros. Son alrededor de seis personas, explicó a EL TIEMPO Luz Janeth Forero, directora de Medicina Legal. La demora en el resultado dependerá en gran medida del estado en el que estén los restos óseos. Según Medicina Legal, el margen de certeza será superior al 99,9 por ciento por tratarse de una comparación entre el ADN de madre e hijo.

El examen determinará, en principio, características como talla, edad, raza e incluso sexo con base en 16 marcadores genéticos. Varios de estos datos serán comparados con información antemortem, como cartas dentales y anteriores intervenciones médicas. El genetista Emilio Yunis dice que si la muestra es de calidad los resultados podrían conocerse en 4 ó 5 días... (Redacción Justicia, eltiempo.com, 10 de Abril, 2010. Noticias Caracol, 31 de marzo, 2010) 
Aquí vemos puntos reveladores referentes a la brevedad de la mención de la genética que, como dijimos arriba, se relaciona con su carácter absoluto y heroico. Al iniciar la noticia, queda claro que la evidencia hallada en la exhumación se asume correspondiente al mayor Guevara. Se precisa incluso que habrá una entrega oficial (no se sabe si física o simbólica) de los restos. Sin embargo, a pesar de la certeza de que los despojos corresponden al mayor, son necesarias pruebas de ADN para corroborar dicha identidad. A manera de explicación se menciona que la madre del militar ya ha entregado una muestra de sangre propia para así cotejar ambas muestras.

Más adelante, se mencionan las personas encargadas de hacer los estudios que van a determinar la identidad de los restos: expertos de la Fiscalía y Medicina Legal "[e]n el grupo hay profesionales en genética, patología, antropología y odontología, entre otros. Son alrededor de seis personas..." (Redacción Justicia, 2010, p.1). Esta forma de presentar a las personas expertas encargadas de establecer la identidad de los restos hace que el papel de los expertos sea pasivo, como si fueran simples espectadores atentos a la voz de la evidencia que habla por sí sola, ello es ejemplo de la idea de brevedad asociada a la modestia ya presentada. Por otro lado, el carácter heroico y certero de la prueba de ADN también queda expuesto cuando quien escribe la noticia dice: "La demora en el resultado dependerá en gran medida del estado en el que estén los restos óseos. Según Medicina Legal, el margen de certeza será superior al 99,9 por ciento por tratarse de una comparación entre el ADN de madre e hijo" (Redacción Justicia, 2010, p.1). Nótese que el hincapié se hace únicamente en que el estado de los huesos puede alterar el tiempo de entrega más no el valor de los resultados.

Siguiendo a Latour, los medios "conserva[n] y extiende[n] todo sin importar que tan equivocado, o extraño, o absurdo sea. ... hace[n] todo móvil pero esta movilidad no es compensada por la adulteración....No importa que tan erróneas sean en principio las huellas [que se dejan en los medios], éstas se volverán correctas como consecuencia de mayor movilidad y mayor inmutabilidad' (Latour, 1990, p.11 - nuestra traducción, énfasis en original). Esta característica está en la noticia anterior cuando aparece: "El examen determinará, en principio, características como talla, edad, raza e incluso sexo con base en 16 marcadores genéticos" (Redacción Justicia, 2010, p.1). A partir de un perfil genético utilizado para identificar un cuerpo o adjudicar una paternidad no es posible (ni relevante) obtener información del tipo que se menciona en la noticia. Esa información la producen los médicos y antropólogos forenses. Sin embargo, esta información errada no quita significación a lo más importante: la prueba de $A D N$ resolverá definitivamente la identidad de los restos. Vemos pues cómo la prueba de ADN tiene el poder de confirmar, de manera incontrovertible, que los restos son de quien dicen ser. Esta forma breve pero contundente de hacer referencia a la genética produce su glorificación, dado que con aquellos resultados se espera "cerrar una de las más dolorosas historias del secuestro en Colombia" (Redacción Justicia, 2010, p.1).

Esta representación de la genética la encontramos también en noticias de genética poblacional, donde es posible ver su carácter breve/heroico/universal/neutro en los medios. La diferencia que hallamos entre los dos tipos de noticias es que en aquellas sobre genética poblacional, la brevedad pero contundencia de la genética no está relacionada con lo corto de su mención dentro de la noticia, sino al número limitado de noticias que aparecen a lo largo de los años.

La siguiente noticia anuncia el inicio de la segunda etapa de la Expedición Humana. Ésta es la primera aparición de noticias referentes al proyecto; la escogimos no sólo por ser la primera de las varias que aparecieron sobre este proyecto, sino porque tanto en ésta, como en otras noticias relacionadas, la representación de la genética responde a ese ideal de ciencia que aparece infatigablemente en los medios de comunicación.

\section{0 médicos buscan raíz del colombiano}

Un equipo conformado por 800 personas, entre antropólogos, sociólogos, músicos, historiadores y médicos, se apresta a iniciar una de las grandes aventuras científicas de los últimos tiempos: la Expedición Humana. Se trata de un viaje de diez meses, a partir del próximo 12 de octubre, por diferentes regiones del país, para encontrar las verdaderas raíces de nuestra cultura, conocer a fondo las características culturales, genéticas y biológicas y a la 
vez estudiar y analizar los problemas socioculturales, de salud y desarrollo que presentan estas comunidades...

... Colombia es, de hecho, el segundo país del mundo en diversidad genética, después de Brasil. Cuenta con unos 80 grupos étnicos diseminados a lo largo y ancho de toda la geografía patria, con unos 700.000 indígenas algunos provenientes de culturas completamente desconocidas, dijo Jaime Bernal. Precisamente, para adentrarse un poco en esas culturas se dará inicio a la gran aventura. Durante diez meses se visitarán cerca de cincuenta grupos. Este recorrido permite complementar un trabajo que adelanta un grupo de científicos y que se inició hace cuatro años, cuando decidieron elaborar el mapa genético del país. Ya se han visitado cerca de cuarenta grupos étnicos y se han recogido unas 2.500 muestras de sangre, las primeras de lo que será el banco genético de Colombia...

....En el mundo se realizan expediciones para conocer a los delfines, las aves y muchas especies animales o vegetales, pero rara vez su objetivo es conocer al hombre, sus raíces. Por eso nos propusimos este trabajo, enfocado a conocer nuestros orígenes. Nos parece que es el mejor homenaje que le podemos hacer a los 500 años del Descubrimiento, dijo Bernal. Otro de los propósitos de la Expedición Humana es ayudar a las comunidades indígenas, buscando que generen sus propios mecanismos de desarrollo, detectando sus necesidades y tratando de promover la intervención de las entidades del Estado en su solución...

(Eltiempo.com, 31 de agosto, 1992)

En esta noticia aparece lo heroico y modesto de la genética y sus servidores. Aquí, quien es protagonista y heroína es la genética, que se presenta como una herramienta certera y veraz para "encontrar las verdaderas raíces de nuestra cultura, conocer a fondo las características culturales, genéticas y biológicas y a la vez estudiar y analizar los problemas socioculturales, de salud y desarrollo que presentan estas comunidades" (Eltiempo.com, 1992, p.1). Es decir, la Expedición Humana, "la gran aventura", promete desenvolver verdades no sólo de carácter genético y biológico sino también anticipar un entendimiento integral de las comunidades que los expedicionarios van a estudiar. Pero de los científicos que van en busca de "la raíz del Colombiano" sabemos solamente algunos datos sobre su disciplina y profesión. Ese silencio de los científicos que aparecen como testigos y traductores de la verdad que guarda la naturaleza reitera lo modesto y apela a lo neutro de quienes practican esa ciencia. Estos expedicionarios, como los científicos que generalmente aparecen en los medios, surgen como seres sin injerencia alguna en las preguntas que hacen o en las respuestas a las que llegan con sus investigaciones. Esta imagen de ciencia que se muestra en medios fortalece esa idea de ciencia universal/blanca/masculina/neutra/objetiva (Haraway, 2004) y que se nutre de la movilización de inmutables (Latour, 1990) para borrar las huellas y las historias de las personas encargadas de hacer ciencia.

A continuación presentamos una segunda manera como los medios ponen en escena la categoría desmarcación/marcación/desmarcación. Nos referiremos a los sujetos que producen los medios y los genetistas y mostraremos ejemplos del movimiento pendular marcación/desmarcación que sobre ellos se aplica y los imaginarios que pone a circular.

\section{Sujetos invisibles}

En las noticias que refieren a genética forense o que tratan sobre genética poblacional, el proceso de invisibilización ocurre también con los sujetos que produce el conocimiento genético. Sin embargo, esta invisibilización opera de manera diferente a lo que ocurre con los sujetos científicos/genetistas y además presenta matices entre los llamamos sujetos de genética forense y los sujetos de genética poblacional. 


\section{Sujetos de genética forense}

En las noticias, los sujetos de genética forense se presentan principalmente de dos maneras: por una parte, aparecen desmarcados de raza o etnia, y por otra, aparecen marcados por clase social y/o lugar geográfico. Como mencionamos previamente, esto se correlaciona con, y es posible, por la puesta en escena de una genética desmarcada y neutral, que no marca explícitamente, sino a través de marcaciones que parecerían inicialmente invisibles.

La desmarcación que observamos tiene que ver con que los sujetos no son, en ningún momento ni en ninguna de las noticias, identificados por medio de categorías raciales o étnicas. Estos sujetos son nombrados generalmente como "víctimas", "cuerpos", "restos", "desaparecidos", "cadáveres", "guerrilleros", "paramilitares" o "NN". Esta información es complementada en algunos casos con datos como edad, sexo, ocupación, filiación, lugar de origen, de la desaparición o del hallazgo, o historia de la desaparición. Veamos un ejemplo:

\section{Cinco cuerpos exhumados en el Guaviare fueron entregados a sus familiares \\ Fueron encontrados en marzo del año pasado, y luego de cotejar las pruebas de ADN, la Unidad Quinta de Justicia y Paz hizo la devolución de los restos. La entrega ocurrió el pasado viernes 4 de septiembre en el hospital de San José del Guaviare... Se trata de Miguel Ángel Valencia, de 60 años; Ramón Elias Valencia Aguilar, de 26, y José Arcángel Valencia Aguilar, de 27. Exhumados en el corregimiento Trocha Ganadera el 10 de marzo del 2008, el padre y los dos hijos desaparecieron en la vereda San Cristóbal el 27 de julio del 2005. (Eltiempo.com, 7 de septiembre, 2009)}

Al preguntarnos por lo que puede significar esta desmarcación racial en las noticias, encontramos, como mencionamos previamente, una similitud con los mecanismos de construcción de lo mestizo. Este proceso se puede interpretar como una forma de construir un imaginario de una Colombia unificada sin diversidad racial o étnica, una nación (mestiza) en la que todos somos iguales, y por lo tanto (en el caso específico de las noticias que retratan a un país en medio de un conflicto armado), en la que todos somos potenciales víctimas.

Interpretamos aquí lo desmarcado como lo mestizo, ya que el mestizo, como categoría dominante, se considera "neutral, no-étnico, no-racial, no-marcado" (Wade, 2002, p.20) ${ }^{9}$. En ese sentido, y dicho de otra manera, interpretamos que la desmarcación en los medios reproduce la idea del mestizo como aquél en el que todos podemos estar incluidos, pero lo hace además apelando a la idea que todos podemos ser víctimas por ser todos colombianos. Como vimos, esta homogenización está soportada por una ciencia genética neutra/que identifica víctimas, resuelve casos, permite la entrega de desaparecidos a sus familias, pero que, como señalamos, no produce diferencias raciales explícitas.

Adicionalmente, encontramos que esta homegenización y el imaginario que construye, se relaciona con lo que dice Bourdieu (1997, p.22-3) acerca de la "acción simbólica de la televisión", que consiste en que los medios presentan información de interés para "todo el mundo y todos los gustos", información que interesa, que no divide y que crea consenso. Esa "información para todos" ayuda a ratificar el papel que tienen los medios en la movilización de inmutables de la que habla Latour (1990). En esa medida, las noticias que presentan sujetos identificados únicamente por su nombre, edad, sexo y en algunos casos lugar de

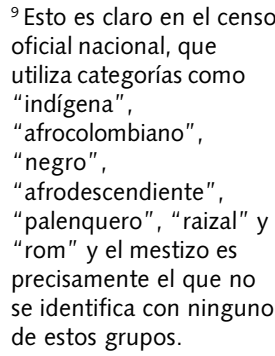


${ }^{10}$ Para tener un ejemplo de la división en regiones que se hace del país en genética poblacional, ver

Rojas et al. (2010). La división en regiones que se usa en la práctica de genética forense está en Paredes et al., 2003.

${ }^{11}$ La consideración de que en Colombia hay una regionalización de la raza también se ha dado en las ciencias sociales. La descripción que Arocha y Moreno (2007) hacen de la construcción de nación asociada al elemento geográfico, o lo que ellos denominan "andinocentrismo" también es útil para interpretar la asociación región-raza en Colombia. Según estos autores, el "andinocentrismo" hace referencia a una ideología de nación del siglo XIX, en la cual la clase dominante estableció una jerarquía regional y de razas, en donde los Andes se ubicaban en la cúspide con sus "gentes más blancas, civilizadas y superiores", en contraposición a las costas

y "tierras bajas", cuya población indígena y negra se consideraba inferior. Mencionan también que este andinocentrismo "no se ha diluido". Además de éste, en Colombia existe una jerarquía racial en términos de lo rural y lo urbano, tal y como apuntan Serrano y Viveros (2006).

12 En el ejemplo siguiente, "antioqueño" se ubica en los Andes, Urabá en la costa Atlántica y el Chocó en la costa Pacífica. El término "pueblerino" indica "perteneciente o relativo a un pueblo pequeño o aldea". procedencia, o víctimas nombradas únicamente como "desaparecidos" o "cuerpos", no dividen a Colombia en víctimas y no víctimas, sino que presentan sujetos que son víctimas y que además podrían ser "cualquier persona". En consecuencia, son noticias que competen a "todo el mundo".

En la siguiente noticia, en donde se hace un llamado abierto a posibles familiares de la víctima que ha sido encontrada, vemos otro ejemplo de desmarcación. La descripción que se provee es tan general, que podría apelar a casi cualquiera.

\section{Confesiones de ex 'paras' permiten hallazgo de restos óseos de desaparecidos en El Dorado (Meta)}

... Una camiseta con el escudo del América de Cali es una de las pocas pistas con que cuenta la Fiscalía para identificar el otro cuerpo, exhumado en la vereda La Meseta de El Dorado, y de quien presumen desapareció entre el 2003 y 2004, por lo que hacen un llamado a quienes consideren que pueda tratarse de su ser querido para que se acerquen a la Unidad de Justicia y Paz. (Eltiempo.com, 13 de mayo, 2009b)

Si bien los sujetos no se marcan en términos raciales, sí son claramente identificados, o marcados, por el lugar geográfico del que proceden o en donde son encontrados, y en algunos casos por clase. La importancia de esta marcación está en que en Colombia, estos lugares están racializados (Wade apud Posso, 2008) y la clase social está atravesada también por categorías raciales. En el primer caso, la desmarcación (racial) y la marcación (geográfica), se pueden interpretar a la luz de lo que ocurre con la práctica de la genética (forense y poblacional) en Colombia, desde donde el país y sus pobladores se dividen en regiones caracterizadas por tener diferentes componentes ancestrales ${ }^{10}$. Un ejemplo ilustrativo de esto lo podemos ver en la siguiente noticia en donde un genetista colombiano se refiere al tema ${ }^{11}$ :

\section{El 85 por ciento de las madres colombianas tiene origen indígena} ...Para Yunis, el [estudio] de la década pasada, que analizó el ADN genómico, evidenciaría que Colombia regionalizó el tema de la raza mediante un mestizaje "selectivo, discriminador hasta el punto de tener regiones negras (Chocó y San Andrés), de predominio caucásico (la zona andina, sobre todo Antioquia y los santanderes) o indígenas (Cauca y Nariño), en lugar de zonas más homogéneas. (Bejarano, 2006)

En ese sentido, si bien los medios no hacen marcaciones raciales (desmarcan), sí marcan a los sujetos al ubicarlos en lugares o regiones del país que han sido racializadas a lo largo de la historia de Colombia. En el siguiente ejemplo los sujetos están desmarcados de raza, pero marcados por lugar geográfico ${ }^{12}$ :

\section{Entregan otros 23 restos de víctimas}

...Finalmente, el cadáver de la joven fue desenterrado por la Fiscalía el 23 de agosto del 2008, pero no había sido entregado a sus familiares mientras se cotejaban las muestras de ADN. Otros figuraban como NN en cementerios pueblerinos o en caminos de zonas aún convulsionadas para el orden público y a los que no entraba la autoridad... Las diligencias de exhumación se efectuaron 
desde febrero del 2007 hasta abril del 2009 en los municipios del occidente, suroeste y oriente antioqueño, Urabá y Chocó.

(Eltiempo.com, 15 de octubre, 2009c)

La siguiente noticia ejemplifica cómo si bien la desmarcación corresponde a lo explícitamente racial, éste es un correlato de una marcación en términos de región ${ }^{13}$ y además de clase social, al referirse a la ocupación del padre de la víctima como "campesino".

\section{Fiscalía entregó restos de $\mathbf{2 5}$ víctimas de la violencia a familias cordobesas}

Los restos correspondían a 22 hombres, 2 mujeres y una adolescente de 14 años de edad, encontrados en fosas comunes por funcionarios de la unidad de Justicia y Paz de la Fiscalía. Luego de la verificación de pruebas de ADN, la Fiscalía pudo comprobar las identidades de los cuerpos que el viernes fueron devueltos a sus parientes debidamente acomodados en nichos mortuorios... Adalberto Paternina, un campesino de puerto Libertador (Córdoba), lloró desconsolado al recibir los restos de su pequeña hija de 14 años, Luz Dary Paternina Alzate, asesinada por paramilitares el 3 de febrero de 2002 en el antiguo corregimiento de San José de Uré, hoy municipio cordobés. (Eltiempo.com, 7 de noviembre, 2009d)

Así, si bien los medios no establecen estas asociaciones explícitamente, al describir a los sujetos por su clase o estatus social, apelan a imaginarios específicos que asocian clase y raza ${ }^{14}$. En el siguiente ejemplo, vemos cómo la clase se menciona a través de eufemismos como "humilde" o al nombrar la ocupación de los sujetos:

\section{Identifican a otra víctima de los 'falsos positivos' en Bogotá}

... En noviembre de ese mismo año, el cuerpo fue exhumado de una fosa común y sometido a pruebas de ADN para establecer su identidad, en el marco de las investigaciones que La Fiscalía inició por las desapariciones de varios jóvenes de Bogotá y Soacha, que luego aparecieron como supuestos integrantes de grupos armados al margen de la ley dados de baja por el Ejército... La nueva víctima identificada de los casos de desaparición forzada con fines de homicidio residía en la localidad de Ciudad Bolívar y era el quinto de seis hermanos. Su progenitora trabaja en una tintorería -en la misma en la que él alcanzó a laborar durante unos días- y su padre es un humilde vendedor ambulante.. (Eltiempo.com, 19 de febrero, 2010 nuestro énfasis)

Es así como en el discurso de los medios, a través de la desmarcación racial y las marcaciones por clase y lugar geográfico, se está haciendo una desmarcación/ marcación simultánea de los sujetos. Esta dualidad en las noticias opera unificando a la población, y construyendo una idea de nación homogénea, neutra (mestiza). Pero también está marcando lo que se aleja de la norma. En Colombia, la norma es precisamente ese mestizo que opera como un mestizo blanqueado que marca al mestizo más oscuro. En este caso, ese mestizo más oscuro puede ser el campesino de Córdoba, el humilde vendedor, la víctima de Urabá. Al hacer esta marcación, los medios generan distancias entre sujetos que están racializados (si
13 Córdoba, departamento ubicado en la costa Caribe colombiana.

\author{
${ }^{14}$ Esta relación raza-clase- \\ región también está \\ presente en el discurso \\ de los genetistas \\ colombianos quienes \\ asocian el tener ancestría \\ negra o indígena y \\ pertenecer a una \\ condición \\ socioeconómica baja. En \\ la antropología, la \\ dinámica entre raza y \\ clase también ha sido \\ objeto de discusión \\ (Wade, 2002; Meertens, \\ Viveros, Arango, 2008).
}


bien los medios no son quienes los racializan), y al hacerlo muestran la heterogeneidad oculta tras la aparente uniformidad. En el contexto del conflicto colombiano, en donde las víctimas tienen diferentes estatus, esta diferenciación va más allá de la raza, por lo que el mensaje es que todos somos iguales y en esa medida todos podemos ser víctimas, pero que en efecto algunos somos menos iguales que otros, y por lo tanto más víctimas que otros.

\title{
Sujetos de genética de poblaciones
}

En las noticias sobre genética poblacional esta marcación/desmarcación también está presente, aunque con una dinámica diferente. A diferencia del caso anterior, vemos un movimiento pendular entre no marcar y marcar.

En este caso, las noticias tratan específicamente de estudios sobre genética poblacional. Por lo tanto, el lenguaje y la manera de describir a los sujetos difieren de las noticias anteriores. Es así como, estas noticias hacen uso constante de categorías raciales como "indio", "indígena", "amerindio", "negro", "afrocolombiano", "afrodescendiente", "europeo", "blanco", "caucasoide", "caucásico" y "mestizo" para describir a la población colombiana.

Aunque en este tipo de artículos la no/marcación también se utiliza para apelar a un imaginario de nación homogénea, de Colombia unida, de "lo que somos todos", ésta se acompaña de una marcación racial explícita que excluye y separa y que convierte a la nación única, singular, en una nación que es múltiple, plural. En algunos casos, como en el siguiente ejemplo, la referencia al "otro" es literal:

\author{
Humana Expedición \\ Colombia no es solo el país de los paisas, los costeños, los cachacos... Es también el \\ segundo país más rico en diversidad étnica en el mundo, con más de ochenta grupos \\ indígenas y comunidades de origen africano, asiático y europeo. Muchos de ellos conforman \\ la otra nación, aquella acostumbrada a andar a pie, en mula o en lancha a pisar la tierra, \\ sentirla y por lo tanto a cuidarla. Aquella que ama la naturaleza, el mar, el agua... En esa otra \\ nación hay lugares adonde aún no llega la polución, ni la contaminación ambiental. Es más, \\ conforman el gran paisaje, el motivo para vivir entre el aire puro, la naturaleza, y sus \\ riquezas... Su proyecto, Expedición Humana, lo asumió la Universidad Javeriana y es \\ dirigido por el genetista Jaime Bernal Villegas. Su propósito es, precisamente, redescubrir y \\ dar a conocer esa otra Colombia. (Ortega Guerrero, eltiempo.com, 1 de febrero, 1993, \\ nuestro énfasis)
}

En estas noticias, con frecuencia se describe inicialmente a Colombia como un país cuya diversidad pareciera un símbolo de orgullo e identidad nacional y no un motivo de exclusión. Todo lo anterior, para que luego esa nación sea dividida en regiones, comunidades, poblaciones diferentes. A eso nos referimos con el movimiento pendular: al juego constante entre "nosotros" y "ellos":

\section{Genes del Valle llegaron de Senegal}

...El trabajo, que analiza la diversidad y el grado de estructura genética presente en el centro y suroccidente colombiano se hizo con base en visitas a comunidades negras, mestizas e indígenas... Dentro de la historia cultural de las poblaciones es interesante conocer la estructura genética de las mismas. Ello nos permite identificar realmente quiénes somos", dice Barreto... No fue sencillo aplicar un estudio con pruebas de ADN, que requiere de muestras de sangre a poblaciones indígenas y negras. Los investigadores tuvieron que explicar varias veces el proyecto a comunidades que se mostraron reacias por una experiencia pasada... El estudio hace parte de una línea de investigación en Univalle, que en los últimos seis años se ha dedicado a precisar la diversidad genética en Valle del Cauca, Cauca, Chocó, Nariño, Tolima, Vaupés y Guaviare. El trabajo sigue porque el objetivo no solo es estudiar las comunidades negras e indígenas de la zona, sino elaborar un mapa genético del país. (Eltiempo.com, 12 de noviembre, 2006a, nuestro énfasis) 
En uno de los fragmentos siguientes, se vecómo la exclusión no sólo recae sobre lo "indígena" y lo "negro", sino que además se articula con lo femenino, que en contraposición a lo masculino es presentado como teniendo una ancestría predominantemente indígena (lo masculino se presenta como europeo) ${ }^{15}$. Es decir, las mujeres aparecen racializadas y los hombres conservan un estatuto de neutralidad.

\section{Cómo ser indio y europeo al mismo tiempo}

La población colombiana es muy joven. Por eso no sorprende que los hallazgos de la biología molecular den pleno soporte a lo que cuenta la historia... Podemos decir entonces que si uno mira la mitocondria una amplia proporción del pueblo colombiano (más del 90 por ciento en algunas partes) tiene ancestro indio. Si mira el cromosoma Y, una amplia proporción tiene ancestro europeo (más del 90 por ciento en algunos lugares), y si mira los otros cromosomas, en algunas partes cerca del 70 por ciento de los genes son de origen europeo. En La Guajira y la costa norte hubo movimientos grandes de gentes por tratarse de puertos y allí los estudios son menos claros. Y el Pacífico es una región de amplísima impregnación africana. (Eltiempo.com, 12 de octubre, 2006b. Nuestro énfasis)

Lo "africano" aparece en la noticia anterior como lo que "impregna". Esta palabra y su uso en el texto nos remite a los escritos de Jiménez López sobre el mejoramiento de la raza en Colombia, en sus palabras, éste se debía llevar a cabo a través de "una corriente de migración europea suficientemente numerosa [que] iría ahogando poco a poco la sangre aborigen y la sangre negra..." (Jiménez López, 1920, p.74). López de Mesa, por su parte, decía que "la sangre oscura resiste en su sucesión de mezclas cinco generaciones y sólo tres la blanca; porque el trópico mata a esta con sevicia; porque la india cede terreno en la lucha vital" (López de Mesa, 1920, p.131).

Más aún, en estas noticias se ve cómo el país que inicialmente aparece unificado (la población colombiana se escribe en singular), posteriormente se multiplica en regiones que se clasifican según el componente ancestral (que equivale a lo racial) que predomina en cada una. Si bien la noticia no habla de "andinocentrismo", esta división del país hace pensar en la noción anteriormente descrita:

El 85 por ciento de las madres colombianas tiene origen indígena ...Ese estudio, para el que se usaron cerca de 80.000 muestras de los 22 grupos sanguíneos conocidos, encontró que en Colombia predomina el componente caucásico (blanco), que oscila entre el 28 por ciento, en la costa del Pacífico, hasta el 68 por ciento de los Llanos Orientales, pasando por el 66 por ciento de la región andina. (Bejarano, eltiempo.com, 13 de octubre, 2006)

Vemos entonces que en los dos tipos de noticias (forense y poblacional), los medios están reproduciendo y movilizando el mestizaje como un mecanismo en el que se "entremezclan la inclusión (pero una inclusión cualificada que privilegia lo más blanco) y la exclusión, la homogenización y heterogeneidad, la diferencia y la similitud" (Wade, 2005, p.255). Están reproduciendo un país que pareciera unificado, singular, pero que se multiplica; el país oficial, el país que Palacios y Safford (2002) Ilamaron "Colombia, país fragmentado sociedad dividida".

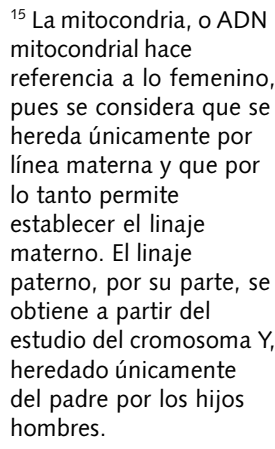




\section{A modo de cierre}

Vimos en este artículo cómo la ciencia genética, tanto forense como poblacional, es presentada en los medios como una ciencia única/uniforme/objetiva/neutra/heroica. Identificamos que esta representación es posible en los medios a través de dos categorías que a la vez funcionan como mecanismos de movilización de ese ideal particular y anacrónico. Nos referimos al estatuto de modestia (que opera a través de la brevedad y el heroísmo) y al movimiento pendular desmarcación-marcacióndesmarcación de la ciencia y sus practicantes.

Mostramos cómo esa representación de la genética no responde ni da cuenta de la naturaleza múltiple de la ciencia ni del quehacer científico. Hay ejemplos en los que la ausencia completa de personas que llevan a cabo los experimentos y la interpretación de los resultados, produce la ilusión de que las pruebas genéticas son agentes autosuficientes capaces de producir conocimiento por sí solas. En esta medida, comparamos la forma en la que la ciencia genética aparece en los medios con lo que Haraway llama el testigo modesto (2004). A la vez, consideramos que esta forma de representación permite movilizar inmutables que consolidan esa idea unificada, objetiva y heroica de la ciencia, tal como lo ha mencionado Latour (1990).

Por otra parte, mostramos que aún a pesar de esa imagen de falsa unidad de la genética, la forma en que ésta aparece en la prensa reproduce dinámicas e ideologías propias de la genética que se hace en Colombia. Vimos cómo la población de país que históricamente se ha asumido oficialmente como unificada (bajo la figura del mestizo), a lo largo de las noticias es separada en partes tanto complementarias como contradictorias para poder entenderla, estudiarla, repararla y controlarla. Esta forma de presentar y de entender la población colombiana en una dinámica pendular que pasa de la singularidad a la multiplicidad, es característica de la forma en la que se conceptualizan, realizan e interpretan las investigaciones genéticas en el país.

\section{Colaboradores}

Todas las autoras participaron en la escritura del artículo en igual medida.

\section{Agradecimientos}

Agradecemos a Olga Restrepo, Tania Arboleda, Natalia Niño, Jimena Zuluaga y Amade $M^{\prime}$ Charek por sus comentarios en la conceptualización y escritura de esta investigación. 


\section{Referencias}

AROCHA, J.; MORENO, L. Andinocentrismo, salvajismo y afroreparaciones. In: MOSQUERA, C.; BARCELOS, L. (Orgs.). Afro-reparaciones: memorias de la esclavitud y justicia reparativa para negros, afrocolombianos y raizales. Bogotá: Universidad Nacional de Colombia (Sede Bogotá), Facultad de Ciencias Humanas, Departamento de Trabajo Social, Centro de Estudios Sociales, 2007. p.523-50.

BEJARANO, B. El 85 por ciento de las madres colombianas tiene origen indígena. Eltiempo.com, Bogotá, Oct. 2006. Disponible en: <http://www.eltiempo.com/archivo/ documento/MAM-2237257>. Acceso en: 3 jun. 2010.

. El 85 por ciento de las madres colombianas tiene origen indígena.

Eltiempo.com, Bogotá, Oct. 2006. Disponible en: <http://www.eltiempo.com/archivo/ documento/CMS-3283434>. Acceso en: 3 jun. 2010.

BIJKER, W.; HUGHES, T.; PINCH, T. The social construction of technological systems: new directions in the sociology and history of technology. Cambridge: MIT Press, 1999.

BOURDIEU, P. Sobre la televisión. Barcelona: Anagrama, 1997.

BUBELA, T.; CAULFIELD, T. Do the print media "hype" genetic research? A comparison of newspaper stories and peer-reviewed research papers. Can. Med. Assoc. J., v.170, n.9, p.1399-407, 2004.

BUENO FISCHER, R. O dispositivo pedagógico da mídia: modos de educar na (e pela) TV. Educ. Pesqui., v.28, n.1, p.151-62, 2002.

COLOMBIA. Ley 975, de 25 de noviembre, de 2005. Por la cual se dictan disposiciones para la reincorporación de miembros de grupos armados organizados al margen de la ley, que contribuyan de manera efectiva a la consecución de la paz nacional y se dictan otras disposiciones para acuerdos humanitarios. Diario Oficial No. 45.980, Congreso de Colombia, Bogotá, 25 Nov. Disponible en: <http://www.secretariasenado.gov.co/ senado/basedoc/ley/2005/ley_0975 2005.html.>. Acceso en: 3 jun. 2010

COSTA, T. The human genome project and the media. Case study: the relation between genetics and the media. JCOM, v.2, n.1, p.1-20, 2003.

ELTIEMPO.COM. 800 médicos buscan raíz del colombiano. Eltiempo.com, Bogotá, Ago. 1992. Disponible en: <http://www.eltiempo.com/archivo/documento/MAM191023>. Acceso en: 3 jun. 2010.

Cinco cuerpos exhumados en el Guaviare fueron entregados a sus familiares. Eltiempo.com, Bogotá, Sept. 2009a. Disponible en: <http://www.eltiempo.com/ archivo/documento/MAM-191023 >. Acceso en: 3 jun. 2010.

Confesiones de ex 'paras' permiten hallazgo de restos óseos de desaparecidos en El Dorado (Meta). Eltiempo.com, Bogotá, May. 2009b. Disponible en: <http:// www.eltiempo.com/archivo/documento/CMS-5183832>. Acceso en: 3 jun. 2010.

Entregan otros 23 restos de víctimas. Eltiempo.com, Bogotá, Oct. 2009c. Disponible en: <www.eltiempo.com/archivo/documento/CMS-6364927>. Acceso en: 3 jun. 2010.

Fiscalía entregó restos de 25 víctimas de la violencia a familias cordobesas. Eltiempo.com, Bogotá, Nov. 2009d. Disponible en: <http://www.eltiempo.com/ archivo/documento/CMS-6536067>. Acceso en: 3 jun. 2010

. Identifican a otra víctima de los 'falsos positivos' en Bogotá. Eltiempo.com Bogotá, Feb. 2010. Disponible en: http://www.eltiempo.com/archivo/documento/ MAM-3847874>. Acceso en: 3 jun. 2010.

Genes del Valle llegaron de Senegal. Eltiempo.com, Bogotá, Nov. 2006a. Disponible en: <http://www.eltiempo.com/archivo/documento/MAM-2268264>. Acceso en: 3 jun. 2010. 
ELTIEMPO.COM. Cómo ser indio y europeo al mismo tiempo. Eltiempo.com, Bogotá, Oct. 2006b. Disponible en: <http://www.eltiempo.com/archivo/documento/CMS3283434>. Acceso en: 3 jun. 2010.

EYCK, T. The media and the public opinion on genetics and biotechnology: mirrors, windows, or walls? Public. Underst. Sci., v.14, n.3, p.305-16, 2005.

FERNÁNDEZ, I. et al. Visiones deformadas de la ciencia transmitidas por la enseñanza. Enseñanza Las Cienc., v.20, n.3, p.477-88, 2002.

GALLEGO, P. Imagen popular de la ciencia transmitida por los cómics. Eureka, v.4, n.1 p.141-51, 2007.

HANSEN, A. Tampering with nature: 'nature' and the 'natural' in media coverage of genetics and biotechnology. Media Cult. Soc., v.28, n.6, p.811-34, 2006.

HARAWAY, D. Testigo_Modesto@Segundo_Milenio. HombreHembra@_Conoce_ Oncoratón®. Barcelona: Editorial UOC, 2004. Cátedra, 1995

Ciencia, cyborgs y mujeres: la reinvención de la naturaleza. Madrid: Ediciones HENDERSON, L.; KITZINGER, J.The human drama of genetics: 'hard' and 'soft' media representations of inherited breast cancer. Sociol. Health Illn., v.21, n.5, p.560-78, 1999.

HENWOOD, K.; PARKHILL, K.; PIDGEON, N. Science, technology and risk perception: From gender differences to the effects made by gender. Equa. Opportun. Int., v.27, n.8, p.662-76, 2008

HIVON, M. et al. Marginal voices in the media coverage of controversial health interventions: how do they contribute to the public understanding of science? Public. Underst. Sci., v.19, n.1, p.34-51, 2005.

IRWIN, A.; WYNNE, B. Misunderstanding science: the public reconstruction of science and technology. Cambridge: Cambridge University Press, 1996.

JIMENÉZ LÓPEZ, M. Primera conferencia. In: LÓPEZ DE MESA, L. (Org.). Los problemas de la raza en Colombia. Bogotá: Biblioteca de 'Cultura', 1920. p.41-78.

KITZINGER, J. Constructing and deconstructing the 'gay gene': media reporting of genetics, sexual diversity and 'deviance'. In: ELLISON, G.; GOODMAN, A. (Orgs). Diversity without deviance: human biology, science and society. London: Taylor and Francis, 2005. p.100-17. Disponible en: <http://www.cardiff.ac.uk/jomec/resources/ KitzingerGayGene.pdf>. Acesso en: 18 ene. 2011.

KOENING, B.; LEE, S.; RICHARDSON, S. Revisiting race in a genomic age. New Brunswick: Rutgers University Press, 2008.

KRIPPENDORFF, K. Metodología de análisis de contenido: teoría y práctica. Barcelona: Paidós, 1990.

KRUSE, C. Producing absolute truth: CSI science as wishful thinking. Am. Anthropol., v.112, n.1, p.79-91, 2010.

LATOUR, B. Science in action: how to follow scientists and engineers through society. Cambridge: Harvard University Press, 1987.

Visualisation and cognition: drawing things together. In: $\mathrm{LYNCH}, \mathrm{M}$.; WOOLGAR, S. (Orgs.). Representation in scientific practice. Cambridge: The MIT Press, 1990. p.19-68.

LAW, J.A. Sociology of monsters: essays on power, technology, and domination. London: Routledge, 1991. 
LÓPEZ DE MESA, L. Tercera conferencia. In: LÓPEZ DE MESA, L. (Org.). Los problemas de la raza en Colombia. Bogotá: Biblioteca de 'cultura', 1920. p.111-49.

MALLON, F. Constructing Mestizaje in Latin America: authenticity, marginality, and gender in the claiming of ethnic identities. J. Latin Am. Anthropol., v.2, n.1, p.170-81, 1996.

MASSARANI, L.; MOREIRA, I.; MAGALHÃES, I. Quando a genética vira notícia: um mapeamento da genética nos jornais diários. Cienc. Ambient., v.26, n.1, p.141-8, 2003

MEERTENS, D.; VIVEROS, M.; ARANGO, L. Discriminación étnico-racial, desplazamiento y género en los procesos identitarios de la población "negra" en sectores populares de Bogotá. In: ZABALA, M. (Org.). Pobreza, exclusión social y discriminación étnico-racial en América Latina y el Caribe. Bogotá: Siglo del Hombre Editores, CLACSO, 2008. p.181-214.

MOUNTCASTLE-SHAH, E. Assessing mass media reporting of disease-related genetic discoveries: development of an instrument and initial findings. Sci. Commun., v.24, n.4, p.458-78, 2003.

ORTEGA GUERRERO, M. Humana Expedición. Eltiempo.com, Bogotá, Feb.1993. Disponible en: http://www.eltiempo.com/archivo/documento/MAM-29949>. Acceso en: 3 jun. 2010.

PALACIOS, M.; SAFFORD, F. Colombia: país fragmentado, sociedad dividida. Su historia. Bogotá: Editorial Norma, 2002.

PAREDES, $M$. et al. Analysis of the CODIS autosomal STR loci in fourma in Colombian regions. Forensic Sci. Int., v.137, n.1, p.67-73, 2003.

PARFITT, T.; EGOROVA, Y. Genetics, mass media and identity: a case study of the genetic research on the Lemba. New York: Routledge, 2006.

PENA, S. Explorando a interface entre a antropologia e a genética. Hist. Cienc. Saude Manguinhos, v.12, n.1, p.221-24, 2005.

PÉREZ-BUSTOS, T. La feminización cultural de las prácticas educativas: etnografías de la popularización de la ciencia y de la tecnología en dos países del sur. CS Rev. Cienc. Soc., v.6, n. 6, p.159-91, 2010

PETERSEN, A. Biofantasies: genetics and medicine in theprintnews media. Soc. Sci. Med., v.52, n.8, p.1255-68, 2001

PIN, R.; GUTTELING, J. The development of public perception research in the genomics field: an empirical analysis of the literature in the field. Sci. Commun., v.31, n.1, p.57-83, 2008.

POSSO, J. Mecanismos de discriminación étnico-racial, clase social y género: la inserción laboral de mujeres negras en el servicio doméstico de Cali. In: ZABALLA, $M$. (Org.). Pobreza, exclusión social y discriminación étnico-racial en América Latina y el Caribe. Bogotá: Siglo del Hombre Editores y Clacso, 2008.

REDACCIÓN JUSTICIA. Hoy la misión es traer los restos de Guevara. Eltiempo.com, Bogotá, Abr. 2010. Disponible en: <http://www.eltiempo.com/archivo/documento/ MAM-3904684>. Acceso en: 3 jun. 2010.

ROJAS, W. et al. Genetic make up and structure of Colombian populations by means of uniparental and biparental DNA markers. Am. J. Phys. Anthropol., v.143, n.1, p.13-20, 2010

SANTOS, R.; MAIO, M., Antropologia, raça e os dilemas das identidades na era da genômica. Hist. Cienc. Saude - Manguinhos, v.12, n.2, p.447-68, 2005. 
SERRANO, J.; VIVEROS, M. Regímenes de ordenamiento social y representaciones de diferencia en Colombia contemporánea. In: CÁCERES, C. et al. (Orgs.). Sexualidad, estigma y derechos humanos: desafíos para el acceso a la salud en América Latina. Lima: CLAM-Ciudadanía Sexual, 2006. p.93-112.

STEMPEL, G.H.; WESTLEY, B.H. (Orgs.). Research methods in mass communication. Englewood Cliffs: Prentice Hall, 1989.

TAMMPUU, P. Constructing public images of new genetics and gene technology: the media discourse on the Estonian human genome project. TRAMES, v.8, n.1-2, p.192-216, 2004

WADE, P. Race, ethnicity and nation: perspectives from kinship and genetics. London: Berghahn Books, 2007.

Rethinking "Mestizaje": ideology and lived experience. J. Lat. Am. Stud., v.37, n.2, p.239-57, 2005.

Race, nature and culture. Virginia: Pluto Press, Sterling, 2002.

DÍAZ DEL CASTILLO, A.; OLARTE SIERRA, M.F.; PÉREZ-BUSTOS, T. Testemunhas modestas e populações invisíveis na cobertura da genética humana na mídia colombiana. Interface - Comunic., Saude, Educ., v.16, n.41, p.451-67, abr./jun. 2012.

Neste artigo apresenta-se a forma como a mídia colombiana configura a prática da genética humana por meio da reprodução de discursos padronizados de ciência que são atravessados pelo gênero e a raça. Para isso, realizamos uma análise etnográfica da cobertura da genética humana (de populações e forense) no principal jornal impresso e no maior telejornal do país nos períodos 1992-2006 (jornal) e 2009-2010 (jornal e telejornal). Nosso argumento é de que, por um lado, a mídia apresenta a ciência da genética como única/uniforme/objetiva/neutra/heróica. Do outro, apresenta sujeitos que são marcados e desmarcados em termos de raça, gênero, classe e geografia. Como conclusão, aponta-se que o último mecanismo reproduz e mobiliza a ideia da mestiçagem como uma ideologia de construção da nação.

Palavras-chave: Testemunha modesta.Genética humana. Mídia. Mestiço. Antropologia Cultural. 
